\title{
PROFIL HEMATOLOGIK BERDASARKAN JENIS PLASMODIUM PADA PASIEN MALARIA RAWAT INAP DI RSK LINDIMARA, SUMBA TIMUR
}

\author{
Henryanto Irawan ${ }^{1}$, Maria Silvia Merry², Y. Nining Sri Wuryaningsih ${ }^{3}$, \\ Tri Baskoro TS 4 \\ ${ }^{1}$ Rumah Sakit Kristen Lindimara \\ 2Bagian Parasitologi Fakultas Kedokteran Universitas Kristen Duta Wacana \\ ${ }^{3}$ Bagian Patologi Klinik Fakultas Kedokteran Universitas Kristen Duta Wacana \\ ${ }^{4}$ Bagian Parasitologi Fakultas Kedokteran Universitas Gadjah Mada
}

Korespondensi: silvia.tropmed@yahoo.com

\begin{abstract}
ABSTRAK
Pendahuluan: Malaria merupakan salah satu penyakit menular yang masih banyak ditemukan di negara tropis dan sub tropis. Data WHO pada tahun 2013 diperkirakan 197 juta kasus malaria dengan angka kematian sekitar 584.000 orang. Di Indonesia kasus malaria pada tahun 2013 sebesar 343.527 kasus. Kabupaten Sumba Timur merupakan daerah endemis malaria dengan angka kejadian malaria yang masih cukup tinggi yaitu sebesar 6.266 kasus.

Tujuan: Menganalisis gambaran hematologik malaria terutama angka eritrosit dan hemoglobin berdasarkan jenis Plasmodium, distribusi berdasarkan data demografi (jenis kelamin, umur, dan pekerjaan) dan rejimen obat anti malaria yang digunakan.

Metode: Penelitian ini bersifat deskriptif analitik dengan menggunakan metode potong lintang. Data berasal dari data rekam medis 262 pasien malaria yang rawat inap di Rumah Sakit Kristen Lindimara bulan Juli 2014 - Desember 2014. Data dianalisis secara univariat dan uji T.

Hasil: Sebanyak 262 subjek penelitian sebanyak 210 orang (80,2\%) terinfeksi Plasmodium falcifarum dan 52 orang $(19,8 \%)$ terinfeksi Plasmodium vivax dengan derajat infeksi ringan $(69,5 \%)$. Hasil uji T terhadap gambaran klinis, angka eritrosit $(p=0,380)$ dan kadar hemoglobin $(p=0,523)$ menunjukkan tidak terdapat perberdaan yang signifikan antara kedua jenis Plasmodium $(p>0,05)$. Berdasarkan distribusi data demografi, frekuensi tertinggi pada perempuan $(53,1 \%)$, umur $\geq 15$ tahun $(54,6 \%)$ dan sebagian besar adalah pelajar $(43,1 \%)$. Rejimen obat anti malaria yang digunakan ialah kombinasi kina dan primakuin $(75,6 \%)$.

Kesimpulan: Kejadian malaria di RSK Lindimara paling banyak disebabkan oleh Plasmodium falcifarum (80,2\%) dibandingkan dengan Plasmodium vivax $(19,2 \%)$. Berdasarkan gambaran klinis, angka eritrosit dan kadar hemoglobin tidak terdapat perbedaan yang signifikan antara kedua jenis Plasmodium $(\mathrm{p}>0,05)$. Kombinasi kina dan primakuin merupakan obat pilihan pertama di RSK Lindimara $(75,6 \%)$.
\end{abstract}

Kata Kunci: Malaria, Plasmodium falcifarum, Plasmodium vivax, hemoglobin, angka eritrosit, antimalaria. 


\title{
HEMATOLOGIC PROFILE BASED ON PLASMODIUM TYPES OF MALARIA INPATIENS IN LINDIMARA CHRISTIAN HOSPITAL, EAST SUMBA
}

\author{
Henryanto Irawan ${ }^{1}$, Maria Silvia Merry², Y. Nining Sri Wuryaningsih ${ }^{3}$, \\ Tri Baskoro TS 4 \\ ${ }^{1}$ Lindimara Christian Hospital \\ ${ }^{2}$ Parasitology Department of Medical Faculty of \\ Duta Wacana Christian University \\ ${ }^{3}$ Clinical Pathology Department of Medical Faculty of \\ Duta Wacana Christian University \\ 4Parasitology Department of Medical Faculty of Gadjah Mada University \\ Correspondence: silvia.tropmed@yahoo.com
}

\begin{abstract}
Background: Malaria is one of the common infectious disease found in tropical and subtropical countries. Based on WHO data in 2013, it was estimated around 179 million cases with approximately 584.000 death rate. Malaria case in Indonesia by year 2013 was approximately 353.527 cases. East Sumba province is a malaria endemic region with high prevalence of cases, estimated 6.266 cases.

Purpose: To investigate the clinical representation of malaria disease based on types of Plasmodium, The distribution based on demography data (gender, age and job level of the patients) and anti-malarial drug rejiment used.

Methode: Descriptive analytic study using cross sectionals method. The data is taken from medical records of 262 malaria patients from Lindimara Christian Hospital in July 2014 - December 2014. Data was analyzed using univariate and T-test.

Results: From 262 of research subjects, 210 people (80,2\%) were infected by Plasmodium falciparum and 52 others $(19,8 \%)$ by Plasmodium vivax with mild degree infections (69,5\%). The T-test result of clinical representation, which were number of erythrocytes $(p=0,380)$ and hemoglobin level $(p=0,523)$ showed insignificant difference between the two types of Plasmodium ( $p>0,05)$. Based on distribution of demography data, the highest frequency of malaria patient was female $(53,1 \%)$, age $>15$ years old $(54,6 \%)$ and most of them are student $(43,1 \%)$. Anti-malarial drug rejiment used was a combination of quinine and primaquine (75,6\%).

Conclusion: The malaria case in the Lindimara Christian Hospital mostly caused by Plasmodium falciparum (80,2\%) than Plasmodium vivax (19,2\%). Based on clinical representation, number of erythrocytes and hemoglobin level showed insignificant difference between the two types of Plasmodium $(p>0,05)$. The combination of kina and primakuin is the drug combination of choice in Lindimara Christian Hospital.
\end{abstract}

Keywords: Malaria, Plasmodium falciparum, Plasmodium vivax, hemoglobin, erythrocyte count, antimalarial treatment. 


\section{LATAR BELAKANG}

Malaria merupakan penyakit menular yang menjadi salah satu penyebab meningkatnya angka kematian bayi, balita dan ibu hamil terutama di negara-negara tropis dan sub tropis. ${ }^{1}$ Data WHO pada tahun 2013 diperkirakan 197 juta kasus malaria dengan angka kematian sekitar 584.000 orang, $78 \%$ kasus diantaranya merupakan kematian anak dibawah usia 5 tahun. ${ }^{2}$ Di Indonesia kasus malaria mengalami penurunan tiap tahunnya dari 417.817 kasus pada tahun 2012 menjadi 343.527 kasus pada tahun 2013. Namun penurunan kasus malaria tidak terjadi diseluruh Provinsi. Kasus malaria masih cukup tinggi di Indonesia bagian Timur seperti Papua, Nusa Tenggara Timur, Papua Barat, Sulawesi Tengah dan Maluku. ${ }^{3}$ Hal ini dikarenakan pengobatan terhadap malaria yang kurang adekuat.

Berdasarkan data Riset Kesehatan Dasar 2013, prevalensi kejadian malaria pada anak $<15$ tahun $(5,9 \%)$ relatif lebih rendah jika dibanding orang dewasa sebesar $6,6 \%$ (35-44). Kasus lebih banyak ditemukan pada laki-laki $(6,2 \%)$ dibanding perempuan (5,8\%). Prevalensi berdasarkan pekerjaan, orang dengan pekerjaan sebagai petani, nelayan, dan buruh beresiko tinggi terhadap penularan malaria $(7,8 \%)$. Penyakit malaria dapat tertular kepada siapa saja tergantung kepada derajat kekebalan dan variasi keterpaparan dengan vector. ${ }^{4}$

Kejadian malaria positif di Provinsi Nusa Tengara Timur sebesar 112.903 kasus yang terjadi di 21 kabupaten dan 1 kota. Kasus malaria di Kabupaten Sumba Timur pada tahun 2012 sebesar 6.266 kasus menduduki peringkat ke-9 tertinggi di Provinsi NTT. 5 Kabupaten Sumba Timur memiliki letak geografis, kelembapan udara, curah hujan, dan suhu yang tinggi sehingga menjadi tempat yang cocok untuk perkembangan dan penularan parasit Plasmodium. ${ }^{6}$

Tujuan dari penelitian ini adalah untuk menganalisis gambaran hematologik pasien khususnya angka eritrosit dan hemoglobin berdasarkan jenis Plasmodium, data demografi (umur, jenis kelamin, dan pekerjaan) pada kejadian malaria dan rejimen obat anti malaria yang digunakan pada pasien malaria di RSK Lindimara.

\section{METODOLOGI PENELITIAN}

Penelitian ini merupakan penelitian deskriptif analitik dengan metode cross sectionals. Data yang akan digunakan adalah data rekam medik pasien malaria yang rawat inap di Rumah Sakit Kristen Lindimara pada bulan Juli Desember 2014. Kriteria inklusi subjek adalah rekam medis pasien malaria yang rawat inap di RSK Lindimara dengan data dan hasil pemeriksaan laboratorium lengkap. Penghitungan kepadatan parasit menggunakan metode semi kuantitatif atau sistem plus. Metode ini merupakan metode yang lebih sederhana untuk menghitung parasite dalam sediaan darah tebal. Sistem ini menggunakan kode $1+$ sampai 4+ dengan 1) += 1 sampai 10 parasit dalam 100 lapang pandang SD tebal. 2) $++=11$ sampai 100 parasit dalam 100 lapang pandang SD tebal. 3$)+++=1$ sampai 10 parasit dalam 1 lapang pandang SD tebal. 4$)++++=>10$ parasit dalam 1 lapang pandang SD tebal. Lokasi penelitian adalah Unit Rekam Medik dan Unit Laboratorium Rumah Sakit Kristen Lindimara Kabupaten Sumba Timur. Penelitian ini dilakukan pada bulan Februari - Maret 2015. Pengumpulan data menggunakan lembar tabel bantu dan kemudian hasil direkapitulasi dan dianalisis 
menggunakan analisis statistik univariat dan uji-T.

\section{HASIL PENELITIAN}

Jumlah total pasien rawat inap pada bulan Juli hingga Desember 2014 di Rumah Sakit Kristen Lindimara adalah 303 pasien, akan tetapi yang memenuhi kriteria inklusi dari penelitian ini adalah 262 pasien.

\section{Data Demografi}

Data demografi yang dianalisis pada pasien meliputi jenis kelamin, umur, dan pekerjaan. Berikut adalah hasil data demografi subjek:

\section{a. Jenis Kelamin}

Tabel 1. Penderita malaria rawat inap di RSK Lindimara berdasarkan jenis kelamin.

\begin{tabular}{lcc}
\hline \multicolumn{1}{c}{ Jenis Kelamin } & N & Presentase (\%) \\
\hline Laki-laki & 123 & 46,9 \\
Perempuan & 139 & 53,1 \\
Total & 262 & 100 \\
\hline
\end{tabular}

Dari tabel 1 di atas yaitu distribusi penderita malaria berdasarkan jenis kelamin, didapatkan perempuan lebih banyak terinfeksi malaria yaitu sebesar 139 orang $(53,1 \%)$ sementara laki-laki sebanyak 123 orang $(46.9 \%)$.

\section{b. Umur}

Tabel 2. Penderita malaria rawat inap di RSK Lindimara berdasarkan umur.

\begin{tabular}{lcc}
\hline \multicolumn{1}{c}{ Kategori umur } & $\mathbf{n}$ & Presentase (\%) \\
\hline $0-11$ bulan & 8 & 3,1 \\
12-23 bulan & 7 & 2,7 \\
2-9 tahun & 63 & 24 \\
10-14 tahun & 41 & 15,6 \\
>15 tahun & 143 & 54,6 \\
Total & 262 & 100 \\
\hline
\end{tabular}

Tabel 2 tentang distribusi penderita malaria berdasarkan umur menunjukkan bahwa penderita malaria yang paling banyak adalah dari golongan usia $>15$ tahun, yaitu sebanyak 143 orang $(54,6 \%)$. Infeksi
Plasmodium juga ditemui pada rentang usia 2-9 tahun (24\%) dan 1014 tahun (15.6\%). Sementara itu, walaupun jarang, malaria juga ditemui pada bayi berusia $0-11$ bulan $(3.1 \%)$.

\section{c. Pekerjaan}

Tabel 3. Penderita malaria rawat inap di RSK Lindimara berdasarkan pekerjaan.

\begin{tabular}{lcc}
\hline & Pekerjaan & Presentase (\%) \\
\hline Petani & 53 & 20,2 \\
Pelajar & 113 & 43,1 \\
Wiraswasta & 16 & 6,1 \\
PNS & 15 & 5,7 \\
Nelayan & 7 & 2,7 \\
Ibu rumah tangga & 19 & 7,3 \\
Belum bekerja & 39 & 14,9 \\
Total & 262 & 100 \\
\hline
\end{tabular}


Tabel 3 tentang distribusi penderita malaria berdasarkan pekerjaan menunjukkan bahwa penderita terbanyak ialah pelajar sebesar 113 orang $(43,1 \%)$. Petani juga terdata banyak mengalami infeksi malaria yaitu sebesar 20,2\%. Wiraswasta dan PNS mempunyai proporsi hampir sama yaitu 16 orang $(6.1 \%)$ dan 15 orang $(5.7 \%)$ masingmasing. Kelompok pekerjaan yang terdata paling sedikit mengalami infeksi adalah nelayan, yaitu sebesar $2.7 \%$.

\section{Jenis Plasmodium}

Dari hasil pemeriksaan laboratorium, terdata 2 jenis Plasmodium penyebab malaria yaitu Plasmodium falcifarum dan Plasmodium vivax pada 262 subjek penelitian seperti pada tabel 4 .

Tabel 4. Penderita malaria rawat inap di RSK Lindimara berdasarkan jenis Plasmodium.

\begin{tabular}{lcc}
\hline \multicolumn{1}{c}{ Jenis Plasmodium } & n & Presentase \\
\hline Plasmodium falcifarum & 210 & 80,2 \\
Plasmodium vivax & 52 & 19,8 \\
Total & 262 & 100 \\
\hline
\end{tabular}

Tabel 4 tentang distribusi berdasarkan jenis Plasmodium menunjukkan bahwa penyebab malaria terbanyak ialah $P$. falcifarum sebesar $80,2 \%$, sedangkan $P$. vivax sebanyak 19.8\%. Jenis Plasmodium lain tidak ditemukan pada pasien. Sementara itu, kepadatan parasit ditemukan bervariasi pada pasien, dari ringan sampai berat. Rincian kepadatan parasit dapat diamati pada Tabel 5.

Tabel 5. Pasien malaria rawat inap di Rumah Sakit Kristen Lindimara pada bulan Juli-Desember 2014 berdasarkan kepadatan parasit.

\begin{tabular}{lccc}
\hline \multicolumn{1}{c}{ Sistem Plus } & P. falcifarum & Plasmodium vivax & Keterangan \\
\hline$(+)$ & $(28,1 \%)$ & $40(76,9 \%)$ & - \\
$(++)$ & $(33,8 \%)$ & $12(23,1 \%)$ & Infesi ringan \\
$(+++)$ & $(36,2 \%)$ & - & Infeksi sedang \\
$(++++)$ & $(1,9 \%)$ & - & Infeksi berat \\
Total & & $52(100 \%)$ & \\
\hline
\end{tabular}

Kepadatan parasit dihitung dengan menggunakan metode semi kuantitatif, dengan positif satu $(+)$ dan dua $(++)$ yang menggambarkan infeksi ringan, positif tiga $(+++)$ menggambarkan infeksi sedang, sampai positif empat $(++++)$ yang menggambarkan infeksi berat. Dari data subjek penelitian didapatkan bahwa sebaran kepadatan parasit pada infeksi $P$. falcifarum didominasi oleh infeksi ringan yaitu $61.9 \%$, sementara sebanyak 36,2\% tergolong infeksi sedang. Ada 1,9\% pasien yang mengalami infeksi berat dengan kepadatan parasit tinggi. Adapun semua pasien yang terinfeksi $P$. vivax semuanya berada dalam tingkat infeksi ringan dengan kepadatan parasit positif satu dan dua.

\section{Gambaran Hematologik}

Sesuai dengan patomekanisme infeksi Plasmodium dengan titik target eritrosit, akan terjadi penurunan pada angka eritrosit dan hemoglobin pasien. Tabel 6 dan 7 berikut adalah rata-rata angka eritrosit dan hemoglobin pada pasien yang terinfeksi $P$. falcifarum dan $P$. vivax. 


\section{a. Angka Eritrosit}

Tabel 6. Analisis univariat dan uji T angka eritrosit $P$. falcifarum dan $P$. vivax.

\begin{tabular}{lccccccc}
\hline \multirow{2}{*}{$\begin{array}{c}\text { Jenis } \\
\text { Malaria }\end{array}$} & \multirow{2}{*}{ n } & \multirow{2}{*}{ Minimum } & \multirow{2}{*}{ Maksimum } & \multirow{2}{*}{ Rerata } & \multicolumn{2}{c}{ IK 95\% } & \multirow{2}{*}{ Nilai P } \\
\cline { 6 - 8 } & & & & & & & \\
Pawah falcifarum & 210 & $2,32 \times 10^{6} / \mu 1$ & $5,7 \times 10^{6} / \mu 1$ & 4.402 & - & - & - \\
$P$. vivax & 52 & $2,45 \times 10^{6} / \mu 1$ & $5,64 \times 10^{6} / \mu 1$ & 4.489 & -0.283 & 0.109 & - \\
\hline
\end{tabular}

Rata-rata angka eritrosit pada pasien yang terinfeksi $P$. falcifarum adalah 4,404 sementara rata-rata angka eritrosit untuk pasien yang terinfeksi $P$. vivax adalah 4.489 . Rerata tersebut tidak berbeda secara signifikan dengan angka $\mathrm{p}>0.05$.

\section{b. Kadar Hemoglobin}

Tabel 7. Analisis univariat dan uji T kadar hemoglobin P. falcifarum dan P. vivax.

\begin{tabular}{lccccccc}
\hline \multirow{2}{*}{$\begin{array}{c}\text { Jenis } \\
\text { Malaria }\end{array}$} & \multirow{2}{*}{ n } & \multirow{2}{*}{ Minimum } & \multirow{2}{*}{ Maksimum } & \multirow{2}{*}{ Rerata } & \multicolumn{2}{c}{ IK 95\% } & \multirow{2}{*}{ Nilai P } \\
\cline { 6 - 7 } P. falcifarum & 210 & $5,7 \mathrm{~g} / \mathrm{d} 1$ & $15,8 \mathrm{~g} / \mathrm{d} 1$ & 11.01 & -0.369 & 0.722 & 0.523 \\
$P$. vivax & 52 & $7,5 \mathrm{~g} / \mathrm{dl}$ & $14,2 \mathrm{~g} / \mathrm{dl}$ & 10.84 & - & - & - \\
\hline
\end{tabular}

Keterangan: Nilai $\mathrm{p}>0,05=$ tidak terdapat perbedaan yang signifikan.

Kadar hemoglobin pada pasien dengan infeksi $P$. falcifarum mempunyai rerata $11.01 \mathrm{~g} / \mathrm{dL}$, sementara pasien yang terinfeksi $P$. vivax adalah $10.84 \mathrm{~g} / \mathrm{dL}$. Rerata tersebut tidak berbeda secara bermakna dengan angka $\mathrm{p}>0.05$.

\section{Rejimen Obat Anti Malaria}

Pengobatan pasien malaria yang rawat inap di RSK Lindimara diberikan sesuai dengan ketersediaan dan rejimen yang disarankan secara nasional. Berikut adalah data penggunaan obat anti malaria pada 262 pasien tersebut.

Tabel 8. Penggunaan obat anti malaria di Rumah Sakit Kristen Lindimara.

\begin{tabular}{lcc}
\hline \multicolumn{1}{c}{ Obat Anti Malaria } & n & Presentase (\%) \\
\hline KINA + PRIMAKUIN & 198 & 75,6 \\
KINA & 64 & 24,4 \\
Total & 262 & 100 \\
\hline
\end{tabular}

Rejimen yang banyak digunakan adalah golongan kina tunggal dan kombinasi antara kina dan primakuin. Dari tabel distribusi penggunaan obat anti malaria di RSK Lindimara terbanyak ialah kombinasi kina dan primakuin sebesar 198 orang $(75,6 \%)$, sedangkan penggunaan kina tunggal sebanyak 64 orang (24.4\%).

\section{PEMBAHASAN}

Hasil penelitian ini menunjukkan bahwa penyebab malaria terbanyak RSK Lindimara ialah $P$. falcifarum sebesar 80,2\%. Serupa dengan penelitian yang dilakukan oleh Firdaus (2014), didapatkan $62,5 \%$ sediaan darah positif $P$. falcifarum. ${ }^{7}$ Plasmodium falcifarum paling banyak ditemukan di Sumba Timur. Hal ini dapat diakibatkan oleh sifat $P$. falcifarum yang banyak dijumpai di wilayah beriklim panas seperti Sumba Timur. ${ }^{8}$ Berbeda dengan penelitian yang dilakukan oleh Ritawati (2012), kejadian malaria terbanyak disebabkan oleh $P$. vivax. Hal ini karena $P$. vivax mempunyai distribusi yang lebih luas 
dibandingkan dengan $P$. falcifarum, mulai dari daerah yang beriklim dingin, subtropis sampai daerah tropis. ${ }^{9}$ Dominasi $P$. falcifarum pada penderita rawat inap di RSK Lindimara disebabkan oleh faktor patomekanismenya yang memiliki tingkat mortalitas yang tinggi sehingga membutuhkan penangan yang lebih intensif, sehingga dokter dan tenaga kesehatan menyarankan pasien dengan infeksi $P$. falcifarum untuk rawat inap. ${ }^{10}$

Distribusi penderita malaria berdasarkan jenis kelamin didapatkan penderita terbanyak ialah perempuan (139 orang) dibandingkan laki-laki (123 orang). Serupa dengan penelitian oleh Gusra (2014), didapatkan penderita malaria terbanyak ialah perempuan sebesar 88,89\%. ${ }^{13}$ Hasil ini berbeda dengan penelitian oleh Solikhah (2012), didapatkan pasien terbanyak ialah laki-laki $(58,8 \%)$, yang diakibatkan oleh faktor pekerjaan. ${ }^{14}$ Penularan pada perempuan biasanya dikaitkan dengan mobilitas yang rendah yang memungkinkan terpapar vektor lebih besar atau keadaan rumah yang dekat dengan tempat perkembangbiakan vector. ${ }^{15}$ Berdasarkan penelitian Hasyim (2014) didapatkan determinan utama kejadian malaria yaitu terdapatnya tempat perindukan nyamuk vektor di sekitar rumah. ${ }^{16}$

Distribusi penderita malaria berdasarkan umur, didapatkan penderita terbanyak berusia produktif > 15 tahun (143 orang). Serupa dengan penelitian oleh Afni (2011), didapatkan penderita malaria terbanyak berusia 15-44 tahun (65,5\%). Hal ini berkaitan dengan akitifitas pada usia produktif yang banyak di luar rumah. ${ }^{17}$ Selain itu usia produktif merupakan usia yang aktif untuk bekerja dan berpindahpindah tempat untuk bekerja atau berpergian ke daerah endemis malaria, sehingga menyebabkan semakin tingginya faktor resiko. ${ }^{14}$
Distribusi penderita malaria berdasarkan pekerjaan didapatkan penderita terbanyak ialah pelajar $(43,1 \%)$. Hal ini kemungkinan disebabkan oleh terpaparnya vektor malaria dirumah akibat kurang pencegahan seperti tidak menggunakan kelambu atau pun obat nyamuk berbeda dengan penelitian yang dilakukan oleh Ritawati (2012), didapatkan kejadian malaria terbanyak pada petani, dan penelitian oleh Solikhah (2012), didapatkan penderita terbanyak adalah pekerja tambang (57,1\%).1,9,14 Petani dan pekerja tambang beresiko tertular malaria karena memiliki lingkungan tempat kerja yang ideal untuk tempat hidup dan berkembangbiaknya nyamuk Anopheles sp. ${ }^{18}$

Berdasarkan kepadatan parasit, infeksi $P$. falcifarum banyak dijumpai dalam tahap infeksi sedang, sedangkan $P$. vivax dijumpai dalam infeksi ringan. berbeda dengan penelitian oleh Firdaus (2014), didapatkan infeksi $P$. falcifarum tergolong dalam infeksi ringan (70\%). ${ }^{7}$ Plasmodium falcifarum dapat melakukan reproduksi kelipatan yang sangat cepat dalam aliran darah, oleh karena itu $P$. falcifarum sering menyebabkan infeksi malaria sedang hingga berat. ${ }^{8}$ Hemolisis intravaskuler pada eritrosit berparasit dan tidak berparasit akan menyebabkan terjadinya anemia. ${ }^{11}$

Sehubungan dengan kepadatan parasit, gambaran hematologik dapat digunakan sebagai indikator keparahan. Pada penelitian ini, gambaran hematologik angka eritrosit dan hemoglobin pada pasien tidak menunjukkan perbedaan yang signifikan antara pasien dengan infeksi $P$. falcifarum dan $P$. vivax $(p>0,05)$. Hal ini disebabkan pengambilan data hanya dilakukan satu kali. Untuk memperlihatkan adanya perbedaan yang signifikan diperlukan data yang berkelanjutan (cohort study) dengan pengambilan 
data pada beberapa waktu. Namun demikian, pada angka minimum, didapatkan angka eritrosit dan kadar hemoglobin penderita dengan infeksi $P$. falcifarum lebih rendah dibandingkan dengan $P$. vivax. Hal ini membuktikan bahwa kerusakan eritrosit lebih banyak ditemukan pada infeksi P. falcifarum. ${ }^{12}$

Pengobatan malaria di RSK Lindimara terbanyak menggunakan kombinasi Kina dan Primakuin $(75,6 \%)$. Kina dan Primakuin menjadi obat pilihan obat yang efektif terhadap malaria berat maupun malaria tanpa komplikasi. ${ }^{4}$ Menurut penelitian yang dilakukan oleh Darnindro (2010), didapatkan kemampuan kina dan kombinasinya lebih lama menurunkan demam dibandingkan dengan derivat artemisin dan kombinasinya. Hal ini dikarenakan kina hanya dapat mengurangi jumlah parasit dalam darah sebesar 1000 parasit perhari, sedangkan derivat artemisin kurang lebih sebesar 10.000 parasit perhari. ${ }^{19}$ Terjadinya perluasan resistensi parasit terhadap kina dan primakuin menjadi salah satu penyebab masih tingginya kasus malaria di Sumba Timur. ${ }^{1}$

\section{KESIMPULAN}

Kejadian malaria di RSK Lindimara lebih banyak disebabkan oleh infeksi $P$. falcifarum $(80,2 \%)$ dibandingkan dengan $P$. vivax $(19,2 \%)$. Berdasarkan gambaran klinis angka eritrosit dan kadar hemoglobin tidak terdapat perbedaan yang signifikan antara kedua jenis Plasmodium $\quad(p>0,05)$ Infeksi terbanyak terjadi pada perempuan $(53,1 \%)$, pada umur $>15$ tahun $(54,6 \%)$ dengan pekerjaan sebagai pelajar $(43,1 \%)$. Kombinasi kina dan primakuin merupakan obat pilihan pertama $(75,6 \%)$.

\section{DAFTAR PUSAKA}

1. Soedarto. Malaria: Epidemiologi global-plasmodium-anophelespenatalaksanaan penderita malaria. Mariyam ed. Jakarta. Sagung Seto: 2011

2. World Health Organization. World Malaria report. (diunduh 19 November 2014) Tersedia dari: http://www.who.int/malaria/wo rld_malaria_report_2012/en/

3. Direktorat Jendral Pengendalian penyakit dan Penyehatan Lingkungan Republik Indonesia. (diunduh 19 November 2014) Tersedia dari: http://pppl. depkes.go.id / berita?id $=1384$

4. Badan Penelitian dan Pengembangan Kesehatan. Riset Kesehatan Dasar 2013 (RISKESDAS). Jakarta. Kementrian Kesehatan Republik Indonesia: 2013

5. Badan Pusat Statistik Provinsi Nusa Tenggara Timur. [diunduh 24 Oktober 2014] Tersedia dari: http://ntt.bps.go.id/index.php/i $\mathrm{d} /$ component/content/article/2 9- data/kesehatan/346-jumlahkasus-hiv-aids-ims-dbd-diare-tbdan-malaria- menurutkabupaten-kota-2012.html

6. Dinas Kesehatan Provinsi Nusa Tenggara Timur. Profil Kesehatan Provinsi NTT Kupang. Depkes Provinsi NTT: (diunduh 4 December 2014) Tersedia dari: http:/ /www.dinkeskotakupang. web.id/bank-data/category/1profil-kesehatan.html? download=17: profil-kesehatannusa-tenggara-timur-ntt

7. Firdaus, A., Irawati, N., Amir, A. Gambaran slide malaria berdasarkan sediaan darah dari Kepulauan Siberut Mentawai. Jurnal Kesehatan Andalas. 2014. 3 (2): pp.94-97.

8. Arsin, A. A. Malaria di Indonesia tinjauan aspek epidemiologi. 
Makassar. Masagena Press: 2012.

9. Ritawati., Yahya. Distribusi spasial malaria di Kecamatan Lengkiti Kabupaten Organ Komering Ulu Provinsi Sumatera Selatan. Jurnal Pembangunan Manusia. 2012. 6 (1): pp 1-12

10. Fuadzy, H., Santi, M. Distribusi kasus malaria di wilayah kerja puskesmas Simpenan Kabupaten Sukabumi. Jurnal Aspirator. 2012. 4 (2): pp. 92-99.

11. Avrina, R., Risniati, Y., Siswantoro, H. Hubungan kepadatan parasit dengan manifestasi klinis pada malaria Plasmodium falcifarum dan Plasmodium vivax. Media Litbang Kesehatan. 2011. 21 (3): pp 119126.

12. Rosdiana, N., Lubis, B. M., Lubis, B., Sutjipto, A. Gambaran hematologi pada anemia akibat infeksi kronis di daerah endemis malaria. Sari Pediatri. 2007. 8 (3) Januari: pp.57-61.

13. Gusra, T., Irawati, N., Amir, N. Gambaran penyakit malaria di puskesmas Tarusan dan puskesmas Balai Selasa Kabupaten Pesisir Selatan. Jurnal Kesehatan Andalas. 2014. 3 (2): pp.234-237.

14. Solikhah. Pola penyebaran penyakit malaria di Kecamatan
Kokap, Kabupaten Kulonprogo. Buletin Penelitian Sistem Kesehatan. 2012. 15 (3) Juli: pp.213-222.

15. Dwithania, M., Irawati, N., Rasyid, R. Insiden Malaria di puskesmas Sungai Durian dan puskesmas Talawi Kota Sawahlunto. Jurnal Kesehatan Andalas. 2013. 2 (2): pp.76-79.

16. Hasyim, H., Camelia, A., Fajar, N. A. Determinan kejadian malaria di wilayah endemis. Jurnal Kesehatan Masyarakat Nasional. 2014. 8 (7): pp.291-294

17. Afni, N. Epidemiologi penderita malaria di wilayah kerja Puskesmas Pantoloan. Jurnal Promotif. 2011. 1 (1) Oktober: pp.14-20.

18. Friaraiyatini., Keman, S., Yudhastuti, R. Pengaruh lingkungan dan perilaku masyarakat terhadap kejadian malaria di Kabupaten Barito Selatan Provinsi Kalimantan Tengah. Jurnal Kesehatan Lingkungan. 2006. 2 (2) Januari: pp.121-128.

19. Darnindro, N., Halim, Y., Sajuni. Studi retrospektif pada pasien malaria falcifarum dengan komplikasi pada Rumah Sakit Umum Bethesda Serukan. Majalah Kedokteran Indonesia. 2010. 60 (1) Januari: pp.22-26. 